\title{
Pericardial Cavity
}

National Cancer Institute

\section{Source}

National Cancer Institute. Pericardial Cavity. NCI Thesaurus. Code C38662.

The potential body space formed between the parietal and visceral layers of the pericardial sac. 